\title{
Cutaneous and Laryngeal Squamous Cell Carcinoma in Mixed Epidermolysis Bullosa, Kindler Syndrome
}

\author{
Hiromi Mizutani ${ }^{a} \quad$ Koji Masuda ${ }^{a}$ Naomi Nakamura ${ }^{a}$ \\ Hideya Takenaka ${ }^{a}$ Daisuke Tsuruta ${ }^{b}$ Norito Katoh ${ }^{a}$ \\ ${ }^{a}$ Department of Dermatology, Kyoto Prefectural University of Medicine, \\ Graduate School of Medical Science, Kyoto, and 'bepartment of Dermatology, \\ Kurume University School of Medicine, Kurume University Institute of \\ Cutaneous Cell Biology, Fukuoka, Japan
}

\section{Key Words}

Cutaneous squamous cell carcinoma - Epidermolysis bullosa - Kindler syndrome . Kindlin-1 $\cdot$ Laryngeal carcinoma

\begin{abstract}
Kindler syndrome is a rare autosomal recessive genodermatosis characterized by traumainduced acral blisters in infancy and childhood, photosensitivity, and progressive poikiloderma. Other clinical features include chronic erosive gingivitis, dysphagia, esophageal and urethral strictures, ectropion, and an increased risk of mucocutaneous squamous cell carcinoma. We describe a patient with Kindler syndrome associated with squamous cell carcinoma of the skin and larynx. He had squamous cell carcinoma on his left knee with simultaneous unresectable laryngeal carcinoma at the age of 43 years. The squamous cell carcinoma on his knee was excised and the laryngeal carcinoma was treated with radiation therapy. Although pathophysiology of Kindler syndrome and its frequency of association with cancer are still not fully elucidated, we speculate that long-term erosion and regeneration of mucosal and cutaneous surfaces may have induced squamous cell carcinoma on the patient's knee and larynx.
\end{abstract}

\section{Introduction}

Kindler syndrome is an autosomal recessive genodermatosis caused by loss-offunction mutations on both alleles of the KIND1 (FERMT1) gene which encodes the protein kindlin-1, also known as kindlerin $[1,2]$, an actin cytoskeleton-focal contact- 
associated protein. Kindler syndrome is characterized by trauma-induced acral blisters in infancy and childhood, progressive poikiloderma, and varying degrees of photosensitivity. Both blistering and photosensitivity tend to diminish with age. Pseudosyndactyly, nail dystrophy, and finger webbing have also been reported. Noncutaneous features comprise desquamative gingivitis, severe periodontitis with loss of teeth, ectropion, and stenosis of the esophagus, anus, vagina, and urethra. In addition, there is also an increased risk of mucocutaneous squamous cell carcinoma [3]. Although more than 100 cases of Kindler syndrome have appeared in the literature since the first report by Kindler in 1954 [4], only a few cases of Kindler syndrome with mucocutaneous squamous cell carcinoma have been reported. Here, we describe a patient with Kindler syndrome associated with squamous cell carcinoma on his left knee with simultaneous unresectable laryngeal carcinoma, which is considered to be extremely rare.

\section{Case Report}

A 43-year-old Japanese man presented with a rapidly growing, fungating skin tumor on his left knee. He had a history of recurring generalized mucocutaneous blistering and erosions since he was 3 years old, and was clinically diagnosed with epidermolysis bullosa. Blisters presented initially over the knees, and later became generalized. When he was 15 years old, he had corneal erosions and scarring on his eyes, and his vision almost became impaired. He has had hoarseness since childhood. He felt dyspnea in his thirties because of laryngeal stenosis and then had a routine laryngeal examination. There is no family history of consanguinity. He had a sibling, but no other family members are affected.

At presentation, a large $(36 \times 25 \mathrm{~mm})$, irregular, ulcerated tumor was present on his left knee. General examination revealed poikiloderma on the face, neck, and extremities with hyperpigmentation and hypopigmentation. Partial hair loss was seen as is the case with generalized atrophic benign epidermolysis bullosa (GABEB), which is known for noncicatricial universal alopecia. Nail dystrophy, corneal scarring, ectropion, dental loss or caries, and atrophic mucosa on the gingiva and palate were also apparent (ig. 1).

A biopsy was performed on his left knee and histopathology showed a tumor mass consisting of atypical squamous cells that proliferated downward into the dermis, the presence of keratinization of individual cells, atypical mitotic figures, and horn pearls, suggesting well-differentiated squamous cell carcinoma (fig. 2). Tumor resection was planned; however, the patient vomited blood just before the operation. He was urgently admitted to our hospital. There was an irregular mass with a rough surface on his epiglottis, which was later revealed to be squamous cell carcinoma (fig. 1f). He was treated with radiation therapy, which reduced the tumor mass size. Surgery on his knee was performed concurrently with radiation therapy. After tumor excision with a $10-\mathrm{mm}$ margin, the defect was repaired with a full-thickness skin graft. The graft took normally in 2 weeks. Currently, he has survived for 2.5 years after surgery and radiation therapy.

Clinically, differential diagnosis in the proband included recessive epidermolysis bullosa dystrophica, GABEB, and Kindler syndrome.

Histology of newly formed blisters on his lower abdomen showed separation between epidermal keratinocytes and the basement membrane. Electron microscopy confirmed hemidesmosomes and desmosomes detached from keratin filaments and multiple planes of cleavage, intraepidermally and within the lamina lucida (fig. $3 a, b)$. Immunofluorescence mapping studies were performed on perilesional skin using monoclonal antibodies against cytokeratin 5 , 14, laminin 332, type VII collagen, $\alpha 6 \beta 4$ integrin, anti-BP180 monoclonal antibody (a kind gift from Prof. J. Jones), and antikindlin-1 antibody (a kind gift from Dr. M.C. Beckerle [5]). Immunofluorescence of the former 7 antibodies was continuous at the basement membrane zone, while anti-kindlin-1 antibody was completely absent in contrast to the staining of kindlin-1 in normal human skin samples, supporting the diagnosis of Kindler syndrome (fig. 3c, d). However, genetic sequencing failed to detect any 
mutation in KIND1. Genetic sequencing of other members of his family could not be performed because they refused. Results of histology, electron microscopy, and immunofluorescence mapping studies strongly suggested that he had Kindler syndrome. Treatment of the patient consisted of sun protection due to photosensitivity and avoiding any trauma because of the increased risk of squamous cell carcinoma. The use of a urethral catheter during surgery was avoided because it may have induced ureter stenosis. The patient now undergoes regular examinations of the larynx and postoperative lesion on his left knee.

\section{Discussion}

Kindler syndrome was first described in 1954 by Theresa Kindler [4]. Since then, more than 100 cases have appeared in the literature. To our knowledge, among more than 100 patients with KIND1 mutations, 5 patients were reported to have squamous cell carcinoma of the lower lip, shoulder, face, hand, and leg [6-8]. Other patients, in whom the molecular basis of Kindler syndrome has not been established, had squamous cell carcinoma of the hard palate, lower lip, hand, and bladder [9-12]. Cutaneous malignant lesions usually develop after the fourth or fifth decade of life, with the exception of a 16-year-old patient with squamous cell carcinoma [6]. To the best of our knowledge, this is the first case of Kindler syndrome with laryngeal carcinoma, and there have only been 2 cases of Kindler syndrome with double cancer [7, 9].

Immunostaining of anti-kindlin-1 antibody assists in the clinical diagnosis of Kindler syndrome $[6,7,13-16]$. Although it remains an invaluable tool, immunostaining of a larger number of cases highlighted that some patients with Kindler syndrome, with loss of function KIND-1 mutations, had almost normal immunohistochemistry results using anti-kindlin-1 antibody [13]. Therefore, KIND1 gene sequencing remains the gold standard in diagnosing this condition, although there are some patients who have distinguishing clinical features of Kindler syndrome without the KIND1 gene mutation [2]. Our case may have carried promoter defects, other cryptic mutations in KIND1, or mutations in focal contact proteins other than KIND1. Alternatively, some unknown abnormalities may have indirectly affected KIND1 gene function in our patient. None of his other family members including a sibling, parents, and grandparents are affected. In order to clarify his condition, the need for genetic sequencing of his family members was emphasized, but it could not be carried out because they refused. Autosomal recessive is the most common mode of inheritance in Kindler syndrome, but dominant transmission and sporadic cases have been reported [17]. Electron microscopy of Kindler syndrome skin often shows extensive reduplication of the lamina densa, focal widening of the lamina lucida, and multiple planes of cleavage, intraepidermally, within the lamina lucida, and sublamina densa [2]. Some of these findings were confirmed in our patient.

Although pathophysiology of Kindler syndrome is still not fully elucidated, it is known that the KIND1 gene product belongs to a family of focal contact proteins that bind several $\beta$ integrin cytoplasmic domains [5]. Kindlin-1 is involved in the regulation of polarity, proliferation, and motility of epidermal keratinocytes [13, 14]. In Kindler syndrome keratinocytes, localization of kindlin-1 is different from normal keratinocytes. In kindlin-1-deficient keratinocytes, localization of kindlin-1 loses its polarity, while it is concentrated at the dermo-epidermal junction zone in normal keratinocytes [14]. It has been reported that kindlin-1 is preferably expressed in the cytoplasm but is reduced in number near the cell periphery [13]. It has also been 
reported that the KIND1 gene is involved in carcinogenesis of certain neoplasms [5]. All of these factors may partly explain the frequent association of cancer in Kindler syndrome. On the other hand, another report argued that the risk of skin cancer remains comparable to that of the control population [9]. Long-term erosion and regeneration of mucosal surfaces may induce squamous cell carcinoma. The role of kindlin-1 in epithelial carcinogenesis needs further investigation.

\section{Disclosure Statement}

None.
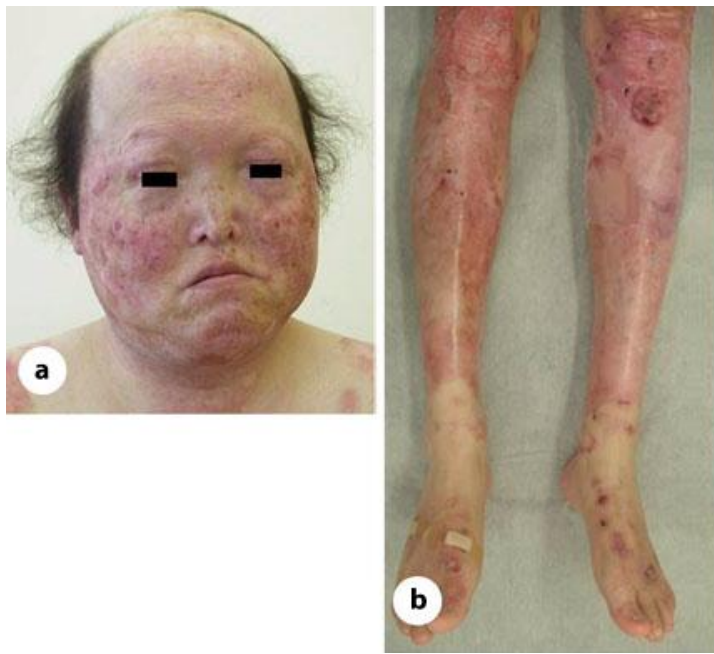
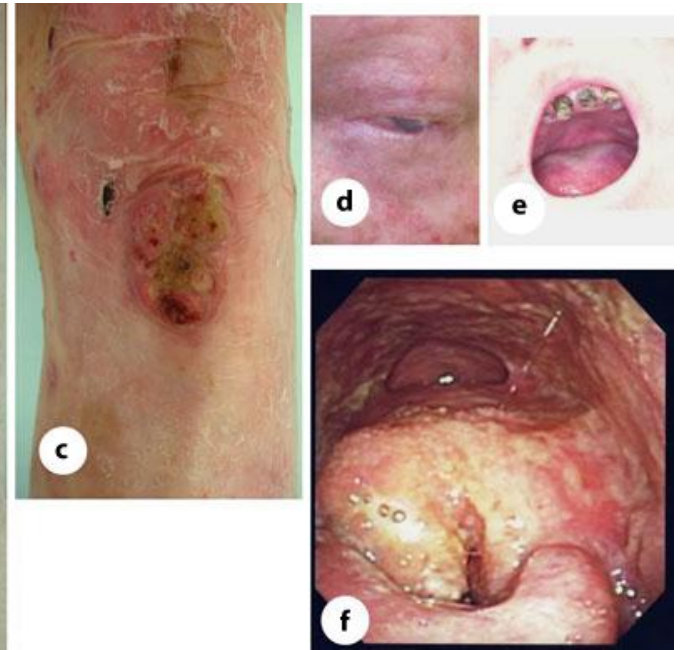

Fig. 1. Clinical features of Kindler syndrome. a, b Poikiloderma with hyperpigmentation and hypopigmentation on the face, neck, trunk, and extremities. c Large, irregular, ulcerated tumor present on the patient's left knee. $\mathbf{d}$ Ectropion and dental loss (e) were evident. $\mathbf{f}$ Laryngoscopic findings. There was an irregular mass with a rough surface on the epiglottis. 


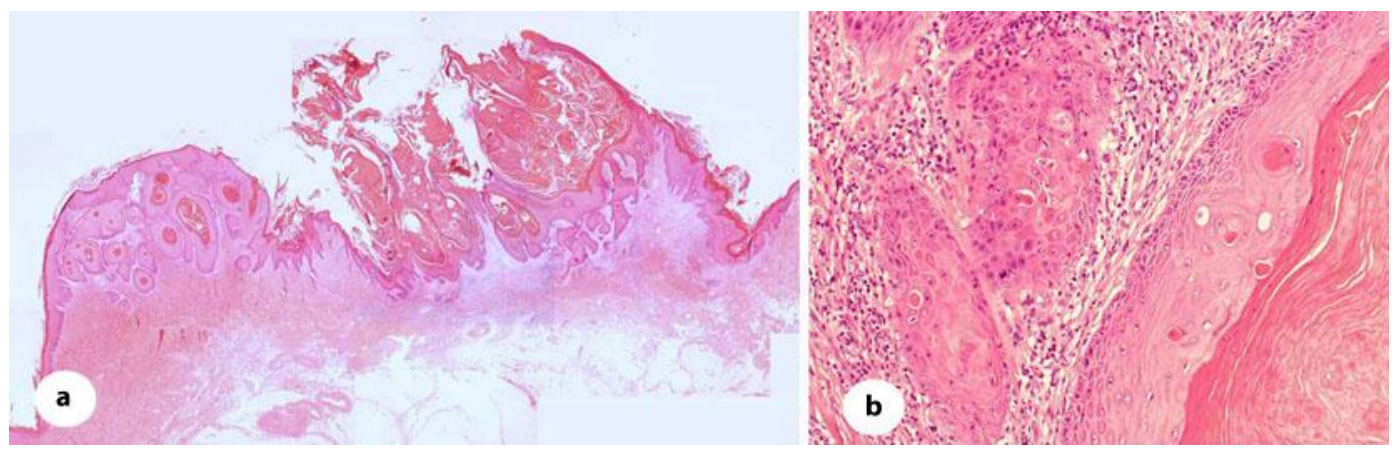

Fig. 2. Histology of excisional specimen of squamous cell carcinoma on the patient's left knee (H\&E stain). a Scanning magnification. Invasive cell masses extended into the dermis. b Abnormal keratinocytes showed marked proliferation and formed horn pearls.
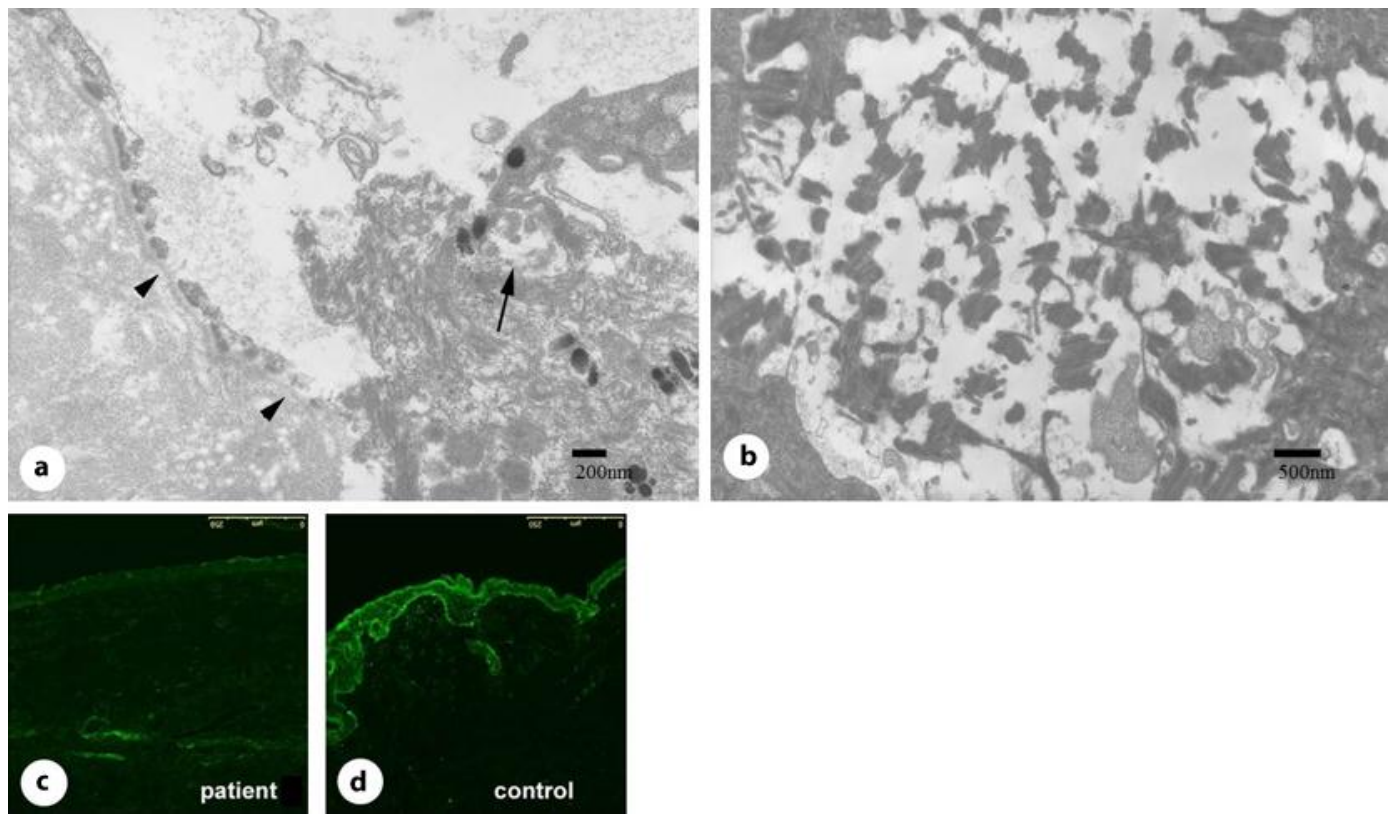

Fig. 3. Ultrastructural and immunohistochemical findings. a Electron microscopy confirmed hemidesmosomes detached from keratin filaments and multiple planes of cleavage intraepidermally (arrow) and within the lamina lucida (arrowheads). b Desmosomes detached from keratin filaments. Immunofluorescence mapping of anti-kindlin-1 antibody was completely absent in the patient's skin section (c) in contrast to kindlin-1staining of normal human skin (d). 


\section{References}

1 Jobard F, Bouadjar B, Caux F, Hadj-Rabia S, Has C, Matsuda F, Weissenbach J, Lathrop M, Prud'homme JF, Fischer J: Identification of mutations in a new gene encoding a FERM family protein with a pleckstrin homology domain in Kindler syndrome. Hum Mol Genet 2003;12:925-935.

-2 Siegel DH, Ashton GH, Penagos HG, Lee JV, Feiler HS, Wilhelmsen KC, South AP, Smith FJ, Prescott AR, Wessagowit V, Oyama N, Akiyama M, Al Aboud D, Al Aboud K, Al Githami A, Al Hawsawi K, Al Ismaily A, Al-Suwaid R, Atherton DJ, Caputo R, Fine JD, Frieden IJ, Fuchs E, Haber RM, Harada T, Kitajima Y, Mallory SB, Ogawa H, Sahin S, Shimizu H, Suga Y, Tadini G, Tsuchiya K, Wiebe CB, Wojnarowska F, Zaghloul AB, Hamada T, Mallipeddi R, Eady RA, McLean WH, McGrath JA, Epstein EH: Loss of kindlin-1, a human homolog of the Caenorhabditis elegans actin-extracellular-matrix linker protein UNC-112, causes Kindler syndrome. Am J Hum Genet 2003;73:174-187.

3 Lai-Cheong JE, McGrath JA: What is Kindler syndrome? Skinmed 2011;9:145-146.

4 Kindler T: Congenital poikiloderma with traumatic bulla formation and progressive cutaneous atrophy. Br J Dermatol 1954;66:104-111.

-5 Kloeker S, Major MB, Calderwood DA, Ginsberg MH, Jones DA, Beckerle MC: The Kindler syndrome protein is regulated by transforming growth factor-beta and involved in integrin-mediated adhesion. J Biol Chem 2004;279:6824-6833.

-6 Arita K, Wessagowit V, Inamadar AC, Palit A, Fassihi H, Lai-Cheong JE, Pourreyron C, South AP, McGrath JA: Unusual molecular findings in Kindler syndrome. Br J Dermatol 2007;157:1252-1256.

-7 Ashton GH, McLean WH, South AP, Oyama N, Smith FJ, Al-Suwaid R, Al-Ismaily A, Atherton DJ, Harwood CA, Leigh IM, Moss C, Didona B, Zambruno G, Patrizi A, Eady RA, Mc Grath JA: Recurrent mutations in kindlin-1, a novel keratinocyte focal contact protein, in the autosomal recessive skin fragility and photosensitivity disorder, Kindler syndrome. J Invest Dermatol 2004;122:78-83.

8 Has C, Wessagowit V, Pascucci M, Baer C, Didona B, Wilhelm C, Pedicelli C, Locatelli A, Kohlhase J, Ashton GH, Tadini G, Zambruno G, Bruckner-Tuderman L, McGrath JA, Castiglia D: Molecular basis of Kindler syndrome in Italy: novel and recurrent Alu/Alu recombination, splice site, nonsense, and frameshift mutations in the KIND1 gene. J Invest Dermatol 2006;126:1776-1783.

$>9$ Has C, Burger B, Volz A, Kohlhase J, Bruckner-Tuderman L, Itin P: Mild clinical phenotype of Kindler syndrome associated with late diagnosis and skin cancer. Dermatology 2010;221:309-312.

10 Emanuel PO, Rudikoff D, Phelps RG: Aggressive squamous cell carcinoma in Kindler syndrome. Skinmed 2006;5:305-307.

-11 Cardin-Langlois E, Hanna D, St-Amant M, Croteau F: Invasive squamous cell carcinoma of the hand in a patient with Kindler syndrome: case report and literature review. Can J Plast Surg 2010;18:e41-e43.

12 Lotem M, Raben M, Zeltser R, Landau M, Sela M, Wygoda M, Tochner ZA: Kindler syndrome complicated by squamous cell carcinoma of the hard palate: successful treatment with high-dose radiation therapy and granulocyte-macrophage colony-stimulating factor. Br J Dermatol 2001;144:1284-1286.

13 Lai-Cheong JE, Ussar S, Arita K, Hart IR, McGrath JA: Colocalization of kindlin-1, kindlin-2, and migfilin at keratinocyte focal adhesion and relevance to the pathophysiology of Kindler syndrome. J Invest Dermatol 2008;128:2156-2165.

14 Herz C, Aumailley M, Schulte C, Schlötzer-Schrehardt U, Bruckner-Tuderman L, Has C: Kindlin-1 is a phosphoprotein involved in regulation of polarity, proliferation, and motility of epidermal keratinocytes. J Biol Chem 2006;281:36082-36090.

-15 Fassihi H, Wessagowit V, Jones C, Dopping-Hepenstal P, Denyer J, Mellerio JE, Clark S, McGrath JA: Neonatal diagnosis of Kindler syndrome. J Dermatol Sci 2005;39:183-185.

-16 Burch JM, Fassihi H, Jones CA, Mengshol SC, Fitzpatrick JE, McGrath JA: Kindler syndrome: a new mutation and new diagnostic possibilities. Arch Dermatol 2006;142:620-624.

17 Nofal E, Assaf M, Elmosalamy K: Kindler syndrome: a study of five Egyptian cases with evaluation of severity. Int J Dermatol 2008;47:658-662. 